\title{
The effect of the addition of alloying elements on carbide precipitation and mechanical properties in 5\% chromium martensitic steels
}

\author{
P. Michaud ${ }^{a, b, d}$, D. Delagnes ${ }^{a, b, *}$, P. Lamesle ${ }^{a}$, M.H. Mathon ${ }^{c}$, C. Levaillant ${ }^{\text {a }}$ \\ ${ }^{a}$ Ecole des Mines d'Albi-Carmaux, CROMeP, Campus Jarlard, Route de Teillet, F-81 013 Albi Cedex 09, France \\ ${ }^{\mathrm{b}}$ Centre d'Elaboration des Matériaux et d'Etudes Structurales, CNRS, 29 rue Jeanne Marvig, BP 94347, F-31055 Toulouse Cedex 4, France \\ ${ }^{\mathrm{c}}$ Laboratoire Léon Brillouin (CEA-CNRS), CEA Saclay, F-91191 Gif-sur-Yvette, France \\ ${ }^{\mathrm{d}}$ Aubert \& Duval, BPI F-63770 Les Ancizes, France
}

\begin{abstract}
Carbide-forming elements ( $\mathrm{W}, \mathrm{Mo}, \mathrm{Nb}, \mathrm{V}$ ), as well as elements that influence only the tempering kinetics (Co, Ni), were added to a 5\% $\mathrm{Cr}$ tempered martensitic steel in order to modify its precipitation. The main goal was to shift the secondary hardening peak towards higher tempering temperatures. Small angle neutron scattering and X-ray diffraction experiments, as well as transmission electron microscopy, were performed to characterize the precipitation of nanometric carbides. A significant modification of the volume fraction and/or chemistry of the very fine secondary precipitation was observed only for Mo, $\mathrm{V}$ and $\mathrm{Ni}$ additions. Moreover, the mechanical properties showed that the volume fraction of small precipitates $\left(\mathrm{VC}, \mathrm{Fe}_{3} \mathrm{Mo}_{3} \mathrm{C}\right.$ ) directly influences the mechanical resistance at high temperature but has a detrimental effect on Charpy impact energy.
\end{abstract}

Keywords: Martensitic steels; Precipitation; Secondary carbides; Yield strength; Impact test

\section{Introduction}

For low-temperature applications $\left(<450{ }^{\circ} \mathrm{C}\right)$, the different possible time-temperature conditions for tempering a martensitic steel lead to a large variety of mechanical properties. Frequently, the tempering conditions can be successfully adapted to the application. Conversely, tempered martensitic steels used for high-pressure die casting or forging tools show a limited lifetime owing to the severe thermo-mechanical working conditions. As the temperature of the tool surface may exceed the tempering temperature, the microstructure after heat treatment rapidly

\footnotetext{
* Corresponding author. Address: Ecole des Mines d'Albi-Carmaux, CROMeP, Campus Jarlard, Route de Teillet, F-81 013 Albi Cedex 09, France. Tel.: +33 (0)5634932 48; fax: +33(0)5 63493242 .

E-mail address: delagnes@enstimac.fr (D. Delagnes).
}

evolves and a sharp decrease in mechanical strength is observed. Moreover, this temperature effect is enhanced by the cyclic plasticity, which also results in a strong softening of the material [1-5].

The flow stress at high temperature of martensitic steels is linked both to the extremely high dislocation density introduced during the martensitic transformation and to the alloyed carbides precipitating above $450{ }^{\circ} \mathrm{C}$ during tempering [6-8]. These main microstructural features theoretically offer several routes to improve high temperature mechanical properties by modifying heat treatment conditions. However, the dislocation density is fixed by the quench conditions, which strongly depend on the tool geometry. Consequently, a slight modification in quench conditions may lead to a disastrous result.

A second route consisting in adjusting the tempering conditions is also limited, as a small variation in tempering 


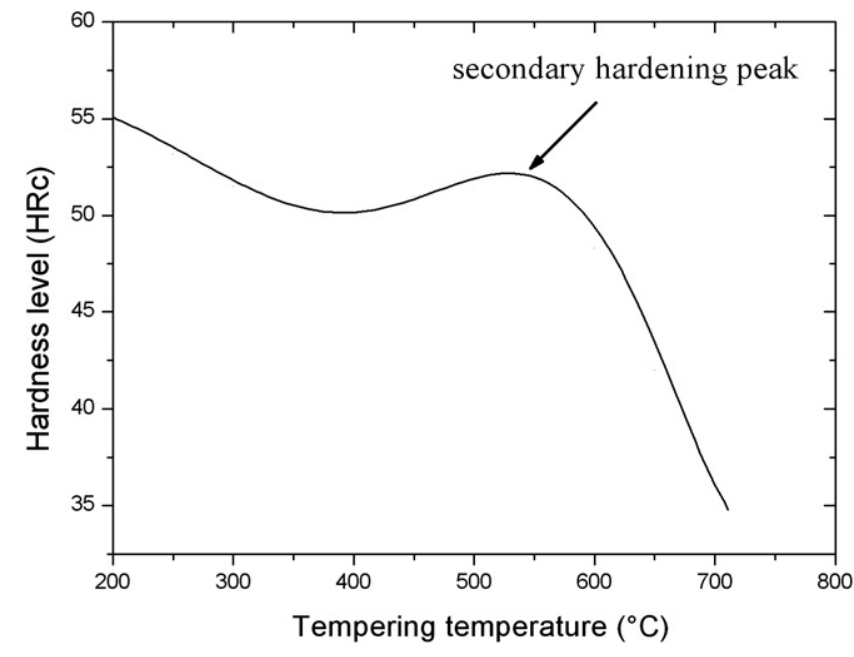

Fig. 1. Hardness level as a function of the tempering temperature showing the sharp softening above the second hardening peak temperature after a single tempering for $2 \mathrm{~h}$ (low-silicon AISI H11 steel).

time or temperature results in a huge effect on the secondary hardening peak as shown in Fig. 1. To prevent such a sharp softening, the basic solution consists of shifting the secondary hardening peak towards higher tempering temperatures. So, introducing alloying elements to modify the secondary precipitation seems to be the more relevant route for casting dies or forging tools. Consequently, carbide-forming elements ( $\mathrm{W}, \mathrm{Mo}, \mathrm{Nb}, \mathrm{V})$ and elements influencing the precipitation kinetics $(\mathrm{Co}, \mathrm{Ni})$ were added to a low-silicon AISI H11 steel previously studied as a reference steel $[5,9]$.

The effects of each added element on carbides precipitation are determined and discussed using electronic microscopy, X-ray diffraction (XRD) and small angle neutron scattering (SANS) experiments. As the thermo-mechanical history of the steel is quite long and complex, before obtaining the final mechanical properties, special attention is paid to the sequence and origin of the precipitation after the annealing stage. The volume fraction of precipitates is then related to the yield strength measured at high temperature as well as the room temperature impact energy. Results are discussed taking into account the precipitation heterogeneity and dislocation-precipitate interaction.

\section{Experimental}

\subsection{Materials}

The chemical composition of the investigated grades is given in Table 1. Each grade is derived from the low-silicon AISI H11 steel (reference) and is simply designated by the modified chemical element(s) from the reference. Heat treatment includes austenitizing, a first tempering at $550{ }^{\circ} \mathrm{C}$ for $2 \mathrm{~h}$ and a second tempering at $605^{\circ} \mathrm{C}$ for $2 \mathrm{~h}$. In this case, the hardness obtained after heat treatment is different for each grade [between 42 and 52 HRc (Rockwell hardness)]. Samples obtained after this treatment were subjected to microstructural investigation and mechanical tests.

Another treatment, only subjected to mechanical tests, was performed with a modified second tempering temperature to obtain $47 \mathrm{HRc}$ for all grades after $2 \mathrm{~h}$ tempering time. As the austenitizing temperature determines the partition of alloying elements between the matrix and carbides phase already precipitated, it is essential that the quantity of carbon in solid solution after quenching remains nearly the same for all grades. Indeed, under these conditions, the same carbon quantity is available for the formation of carbides during tempering and comparison between the different grades becomes particularly relevant.

As one role of the primary carbides is to prevent the coarsening of grain size during austenitization [10], the control of the primary carbide fraction before quenching is of first importance. The austenitization conditions of each grade are calculated considering a constant molar fraction of undissolved primary carbide, $f_{\text {mol }}$, using ThermoCalc ${ }^{\circledR}$. First, $f_{\text {mol }}$ is calculated from the equilibrium phase diagram of the reference grade obtained with ThermoCalc $^{\circledR}$ (Fig. 2). A fraction of carbides equal to $0.4 \%$ is supposed to be optimized as the austenitic grain size of the reference is sufficiently small (around $10 \mu \mathrm{m}$ [11]) to obtain suitable mechanical properties. The austenitization temperature is then calculated for each grade plotting the molar fraction of carbides vs. the austenitizing temperature for the same treatment duration. Depending on the alloying elements, the austenitization temperature lies between $976^{\circ} \mathrm{C}$ and $1060^{\circ} \mathrm{C}$. Prior austenitic grain size was systematically controlled using the Köhn method after heat treatment to check if the calculated temperature is correct. In every case, the grain size was close to that of the reference grade. Details of the calculation and results obtained are available in Ref. [12].

\subsection{Mechanical tests}

Tensile tests were carried out on a $250 \mathrm{kN}$ closed loop servo-hydraulic testing machine equipped with a $6 \mathrm{~kW}$ induction generator and a three zones coil configuration. The complete experimental set up is presented in Ref. [4]. The axial strain was measured with a $10 \mathrm{~mm}$ gauge length extensometer. Tensile tests were performed at $550{ }^{\circ} \mathrm{C}$, which is the usual temperature reached by the tool surface during high-pressure die casting operations [13]. Charpy impact tests were performed at room temperature on a Roell Amsler RKP 300. Conventional Charpy V-notched specimens were used with an $80 \mathrm{~mm}^{2}$ area under the notch.

\subsection{Microstructural investigations}

The tempered martensitic microstructure was investigated by scanning electron microscopy (SEM), transmission electron microscopy (TEM) equipped with an energy-dispersive X-ray analyser and XRD. Carbides were extracted from the martensitic matrix using the replica 
Table 1

Chemical composition (wt.\%) of the investigated grades

\begin{tabular}{|c|c|c|c|c|c|c|c|c|c|c|}
\hline Grades & $\mathrm{C}$ & $\mathrm{Si}$ & $\mathrm{Mn}$ & $\mathrm{Ni}$ & $\mathrm{Cr}$ & Mo & $\mathrm{V}$ & Co & W & $\mathrm{Nb}$ \\
\hline Reference & 0.35 & 0.28 & 0.35 & 0.06 & 5.11 & 1.21 & 0.47 & - & - & - \\
\hline W & 0.35 & 0.20 & 0.33 & 0.06 & 5.05 & 1.22 & 0.45 & - & 1.21 & - \\
\hline MoMo & 0.38 & 0.22 & 0.35 & 0.10 & 5.04 & 2.74 & 0.47 & - & - & - \\
\hline MoMoCo & 0.38 & 0.29 & 0.32 & 0.16 & 4.96 & 2.78 & 0.47 & 2.58 & - & - \\
\hline $\mathrm{Nb}$ & 0.36 & 0.22 & 0.35 & 0.10 & 5.03 & 1.31 & 0.48 & - & - & 0.07 \\
\hline $\mathrm{Ni}$ & 0.35 & 0.28 & 0.36 & 1.42 & 5.13 & 1.21 & 0.46 & - & - & - \\
\hline $\mathrm{NiNi}$ & 0.35 & 0.28 & 0.35 & 2.93 & 5.27 & 1.23 & 0.47 & - & - & - \\
\hline Mo & 0.33 & 0.28 & 0.36 & 0.09 & 5.10 & 1.83 & 0.46 & - & - & - \\
\hline VV & 0.34 & 0.29 & 0.34 & 0.02 & 5.11 & 1.23 & 0.84 & - & - & - \\
\hline $\mathrm{Co}$ & 0.35 & 0.26 & 0.35 & 0.07 & 5.24 & 1.23 & 0.47 & 2.72 & - & - \\
\hline NiMo & 0.33 & 0.28 & 0.35 & 1.83 & 5.18 & 1.83 & 0.47 & - & - & - \\
\hline NiW & 0.36 & 0.29 & 0.35 & 1.85 & 5.25 & 1.23 & 0.47 & - & 1.65 & - \\
\hline $\mathrm{NiV}$ & 0.36 & 0.28 & 0.36 & 1.82 & 5.19 & 1.22 & 0.72 & - & - & - \\
\hline
\end{tabular}

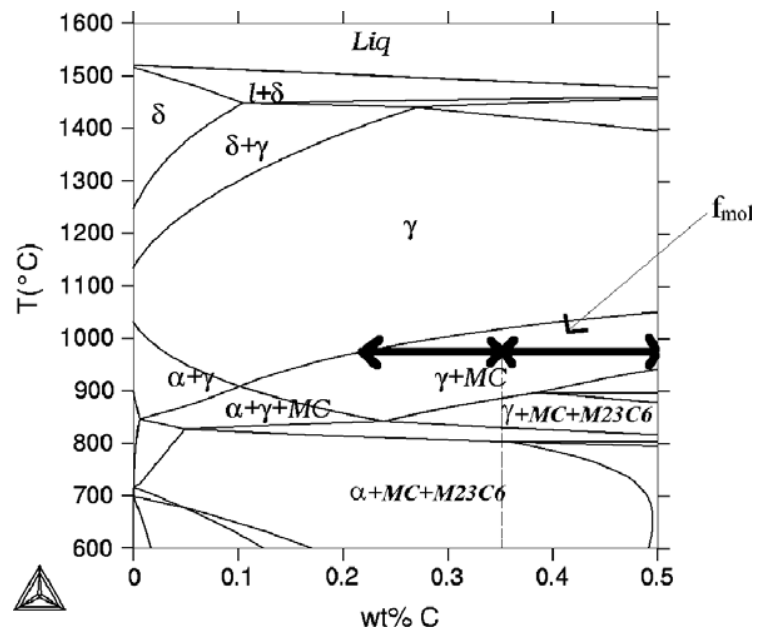

Fig. 2. Equilibrium phase diagram of the reference grade calculated by ThermoCalc ${ }^{\circledR}$ giving the proportion of carbides in the austenitic matrix.

technique in order to avoid a contribution from the matrix to the chemical analysis [9] performed by energy dispersive $\mathrm{X}$-ray spectroscopy (EDXS) and to the crystallographic structure determination by selected area diffraction. To determine the crystallographic structure by XRD, carbides were previously extracted from the martensitic matrix using a dissolution technique for the martensitic matrix described in Ref. [14]. XRD experiments were performed using a PANALYTICAL X'PERT PRO diffractometer equipped with a $\mathrm{Cu} \mathrm{K} \alpha$ radiation source and a graphite crystal monochromator and scintillation counter.

The small size of the precipitates makes them difficult to quantify by direct electronic microscope observations and above all, the analysed volume is too small to deduce significant information. To obtain better statistics on the size distribution as well as the volume fraction of secondary carbides, SANS experiments were performed at the Léon Brillouin Laboratory (CEA-CNRS), on a PAXE smallangle instrument. The wavelength $\lambda$ was $0.6 \mathrm{~nm}$ and the sample-to-detector distance $(D)$ was $2 \mathrm{~m}$, covering a scattering vector $(q)$ range from 0.25 to $1.6 \mathrm{~nm}^{-1}$ ( $q=4 \pi \sin \theta / \lambda$ where $2 \theta$ is the scattering angle). Measure- ments were performed at room temperature, under a saturating magnetic field $H=2 \mathrm{~T}$ perpendicular to the incident neutron beam direction, in order to separate magnetic and nuclear scattering cross-sections. The measured intensities were corrected using the standard computer programs of the Léon Brillouin Laboratory for sample transmission, background intensity as well as detector response [15]. The analysis method has been reported elsewhere $[9,16]$. In the case of ferromagnetic materials, the SANS intensity is the result of two contributions, a nuclear and a magnetic one, which depend respectively on the difference in composition and in magnetization between the particles and the matrix. In terms of cross-section, the SANS intensity can be written as

$$
\begin{aligned}
I(q)= & \frac{1}{V_{\mathrm{p}}} \frac{\mathrm{d} \Sigma}{\mathrm{d} \Omega}(q)=f_{\mathrm{p}}\left[\Delta \rho_{\mathrm{nucl}}^{2}+\Delta \rho_{\mathrm{mag}}^{2} \sin ^{2} \alpha\right] \\
& \times \frac{\int_{0}^{\infty} h(R) V^{2}(R) F^{2}(q, R) \mathrm{d} R}{\int_{0}^{\infty} h(R) V(R) \mathrm{d} R}
\end{aligned}
$$

where $I$ is the scattered intensity, $V_{\mathrm{p}}$ the sample irradiated volume, $\mathrm{d} \Sigma / \mathrm{d} \Omega$ the macroscopic differential cross-section, $f_{\mathrm{p}}$ the volume fraction of precipitate and $\alpha$ the angle between the magnetization of the sample and the scattering vector $q$. As the majority of small precipitates observed in TEM have a spherical shape [9], the particle form factor $F(q, R)$ for spherical particles with a radius $R$ was used. $V(R)$ is the volume of a spherical particle of radius $R$. $h(R)$ is the size distribution function, which is supposed to be a symmetric normalized Gaussian distribution.

$\Delta \rho_{\text {nucl,mag }}$ are the nuclear and magnetic contrast terms given by:

$\Delta \rho_{\text {nucl,mag }}=\frac{b_{\text {nucl,mag }}^{\mathrm{p}}}{v_{\mathrm{at}}^{\mathrm{p}}}-\frac{b_{\mathrm{nucl}, \mathrm{mag}}^{\mathrm{m}}}{v_{\mathrm{at}}^{\mathrm{m}}}$

where $b$ is the nuclear or magnetic mean scattering length in the precipitates $(\mathrm{p})$ or in the matrix $(\mathrm{m})$, and $v_{\mathrm{at}}^{\mathrm{p}, \mathrm{m}}$ is the mean atomic volume either of the precipitates or the matrix.

As the magnetic moments lie parallel to the field $H$, the magnetic scattered intensity is zero in that direction and maximum in the normal direction. Consequently, the 
nuclear cross-section can be measured at $\alpha=0$, while the sum of the nuclear and the maximum magnetic cross-section is measured at $\alpha=\pi / 2$. Subsequently, the magnetic contrast can be calculated by a simple subtraction. Some information about chemical composition can be deduced from the ratio between those two quantities, called $A$-ratio.

For chemically and magnetically homogeneous particles, the $A$-ratio depends on the chemical composition, magnetization and atomic density variations between precipitates and the matrix, and is given by:

$A=\frac{(\mathrm{d} \Sigma / \mathrm{d} \Omega)_{\perp \vec{H}}}{(\mathrm{~d} \Sigma / \mathrm{d} \Omega)_{\| \vec{H}}}=\frac{\Delta \rho_{\mathrm{nucl}}^{2}+\Delta \rho_{\mathrm{mag}}^{2}}{\Delta \rho_{\text {nucl }}^{2}}=1+\frac{\Delta \rho_{\mathrm{mag}}^{2}}{\Delta \rho_{\text {nucl }}^{2}}$

Eq. (1) was used to fit the experimental data. The procedure is precisely described in $[9,16]$. The factor $\mathrm{C}=f_{\mathrm{p}}$ $\left[\Delta \rho_{\text {nucl }}^{2}+\Delta \rho_{\text {mag }}^{2} \sin ^{2} \alpha\right]$, which contains the volume fraction of particles, is independent of the size distribution and is considered to be a fitting parameter. The mean size of the particles (radius $R$ ) as well as the full width at the half maximum of the Gaussian distribution were also obtained.

\section{Results}

\subsection{Influence of alloying addition on carbides precipitation}

\subsubsection{Chemical composition}

Two populations of secondary carbides were identified by TEM (cf. Fig. 3a and b) and SANS on the reference grade (low-silicon AISI H11 steel) [5,9]:

- small carbides (radius around $1.5 \mathrm{~nm}$, standard deviation $\cong 0.2 \mathrm{~nm}$ ): this first population includes mainly vanadium carbides (MC type) and a smaller quantity of chromium carbides $\left(\mathrm{M}_{7} \mathrm{C}_{3}\right.$ type $)$.
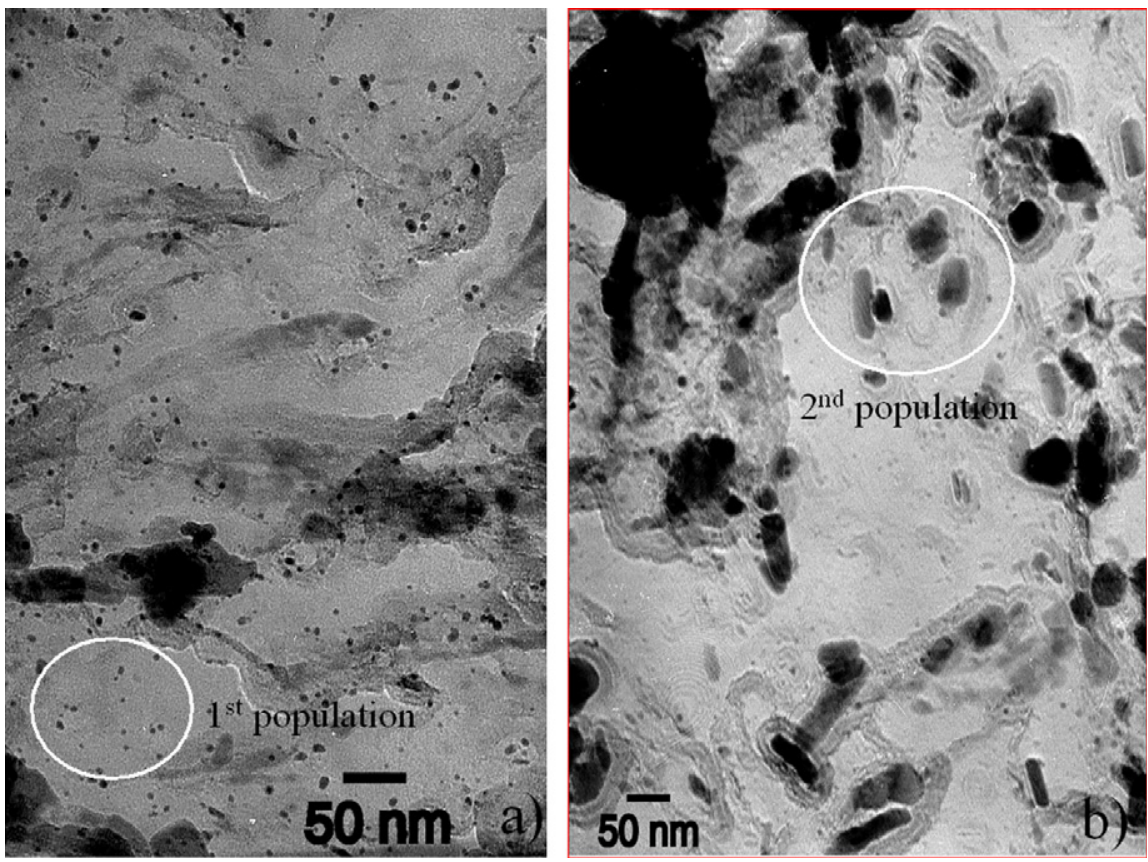

Fig. 3. ( $a$ and b) Bright field TEM images of the two different populations of secondary carbides (reference grade, replica).
- carbides with a radius between $15 \mathrm{~nm}$ and $20 \mathrm{~nm}$ estimated by both SANS and TEM (standard deviation $\cong 1.5 \mathrm{~nm}$ by SANS and $\cong 5 \mathrm{~nm}$ by TEM): this second population includes mainly chromium carbides $\left(\mathrm{M}_{7} \mathrm{C}_{3}\right)$ and a significant quantity of vanadium carbides (MC).

The identification of these populations is performed using three complementary experiments: XRD after dissolution of the matrix, electronic diffraction and comparison between experimental and theoretical $A$-ratios $[9,16]$ using scattered intensity obtained by SANS. With the SANS experimental configuration previously described, the quantification is only possible for the first population of carbides [17].

In addition, a third population of bigger iron carbides $\left(\mathrm{M}_{3} \mathrm{C}\right)$, chromium carbides $\left(\mathrm{M}_{23} \mathrm{C}_{6}\right)$ and vanadium carbides (MC) in the range $50-300 \mathrm{~nm}$ was observed. However, the density of these carbides is very low compared to the number of carbides belonging to the populations described above. Moreover, large $\mathrm{M}_{23} \mathrm{C}_{6}$ and $\mathrm{MC}$ carbides were identified in the as-quenched sample showing that these two types of carbide were only partially dissolved during the austenitization. The four types of carbides identified on the reference grade are shown in Fig. 4.

For all the investigated grades, a first and second population of carbides (respectively radius around $1.5 \mathrm{~nm}$ and $15 \mathrm{~nm}$ ) were observed. Modification of the chemical composition has not significantly influenced the average size of both populations observed by SANS. Conversely, the population of larger carbides was modified in some cases. The different types of identified carbides are given in Table 2. As $\mathrm{Nb}, \mathrm{Mo}$ and $\mathrm{W}$ are strong carbide formers, the chemical composition of precipitates is modified. Niobium carbides (Type $\mathrm{MC} \approx \mathrm{NbC}$ ), molybdenum carbides (type 

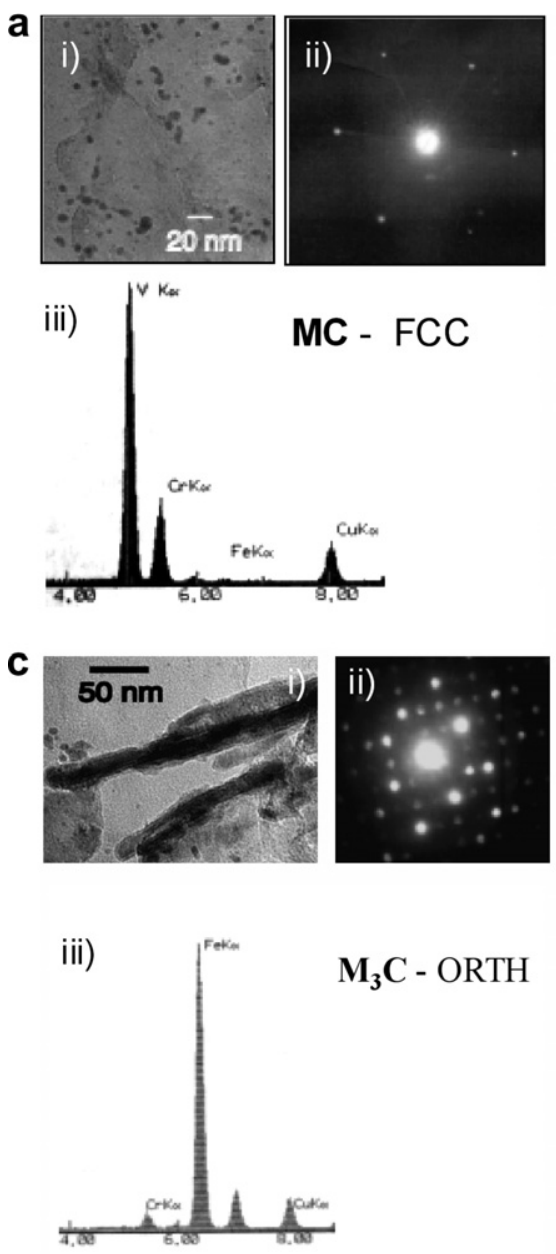
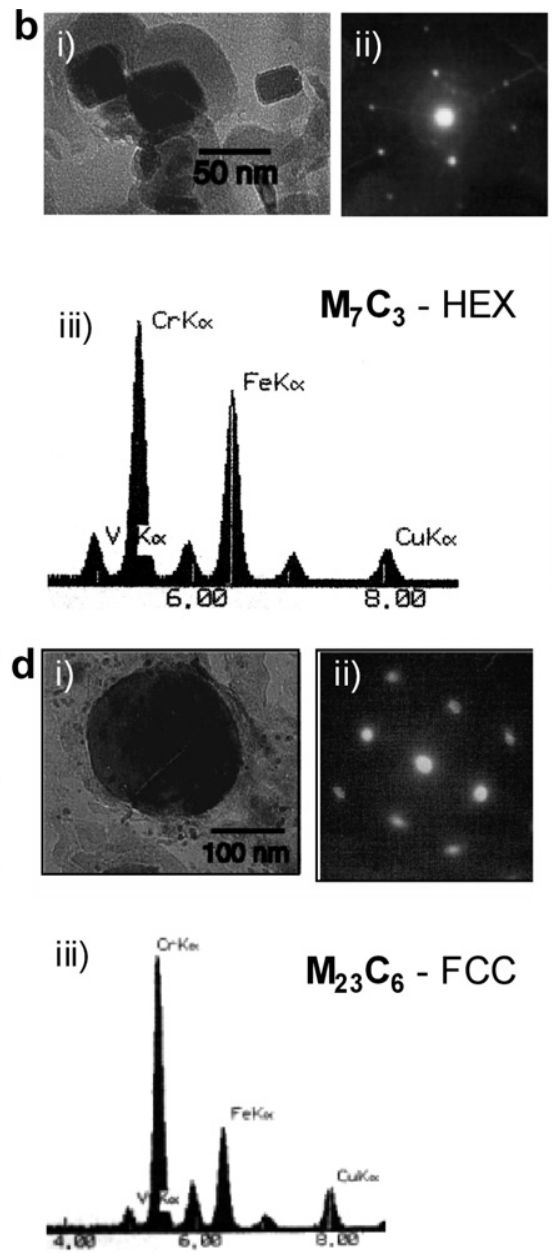

Fig. 4. Carbides morphology observed by TEM (bright field image, replica) (i), EDXS analysis (ii), electronic diffraction pattern (iii) for the four types of identified carbides: (a) $\mathrm{MC}$, (b) $\mathrm{M}_{7} \mathrm{C}_{3}$, (c) $\mathrm{M}_{3} \mathrm{C}$ and (d) $\mathrm{M}_{23} \mathrm{C}_{6}$ in the reference grade.

Table 2

Identified carbides for each grade of modified AISI H11 steels

\begin{tabular}{ll}
\hline Grades & Carbides \\
\hline Reference & $\mathrm{MC}(\approx \mathrm{VC}), \mathrm{M}_{3} \mathrm{C}\left(\approx(\mathrm{Fe}, \mathrm{Cr})_{3} \mathrm{C}\right)$, \\
& $\mathrm{M}_{23} \mathrm{C}_{6}\left(\approx(\mathrm{Cr}, \mathrm{Fe})_{23} \mathrm{C}_{6}\right), \mathrm{M}_{7} \mathrm{C}_{3}\left(\approx(\mathrm{Cr}, \mathrm{Fe})_{7} \mathrm{C}_{3}\right)$ \\
$\mathrm{W}, \mathrm{NiW}$ & Reference $+\mathrm{M}_{6} \mathrm{C}\left(\approx \mathrm{Fe}_{3} \mathrm{~W}_{3} \mathrm{C}\right)$ \\
$\mathrm{Mo}, \mathrm{MoMo}, \mathrm{MoMoCo}$ & Reference $+\mathrm{M}_{6} \mathrm{C}\left(\approx \mathrm{Fe}_{3} \mathrm{Mo}_{3} \mathrm{C}\right)$ \\
$\mathrm{Nb}$ & Reference $+\mathrm{MC}(\approx \mathrm{NbC})$ \\
$\mathrm{Ni}, \mathrm{NiNi}, \mathrm{VV}, \mathrm{Co}, \mathrm{NiV}$, & $=$ Reference \\
$\quad \mathrm{NiMo}$ & \\
\hline
\end{tabular}

$\mathrm{M}_{6} \mathrm{C} \approx \mathrm{Fe}_{3} \mathrm{Mo}_{3} \mathrm{C}$ ) as well as tungsten carbides (type $\mathrm{M}_{6} \mathrm{C} \approx \mathrm{Fe}_{3} \mathrm{~W}_{3} \mathrm{C}$ ) were identified using XRD, electronic diffraction, EDXS and SANS. Ni and $\mathrm{Co}$ are not carbideforming elements and as expected, no modification of the type of precipitates from the reference grade was observed. Addition of vanadium results in a higher quantity of vanadium carbides observed in the VV grade.

\subsubsection{Distribution of carbides among the different populations}

For the $\mathrm{Nb}$ grade, the added niobium precipitates totally into large niobium carbides which were not dis- solved during the austenitization. Conversely, the secondary precipitation was not modified by the niobium addition for the adopted condition of austenitization. Consequently, the main goal of offering numerous pinning obstacles for dislocations is not reached with niobium addition. This conclusion is also true for tungsten for the investigated composition. Indeed, large "undissolved" tungsten carbides were also observed (Fig. 5). On the contrary, additions of vanadium and molybdenum modify the secondary precipitation, as indicated in Table 3.

\subsubsection{Volume fraction of small carbides}

The volume fraction of the first population concerning the smallest size precipitates is calculated from SANS experiments. An estimation can be obtained from the factor $C$ provided that nuclear and/or magnetic contrasts can be evaluated $[9,16]$. In this case, the chemical composition of carbides should be previously determined. Using TEM observations associated with electronic diffraction and EDXS, XRD, as well as the calculated $A$-ratio for large values of $q$, the hypothesis of a first population including only vanadium carbides is relevant [9] except for high molybdenum content grades (Mo, MoMo, 


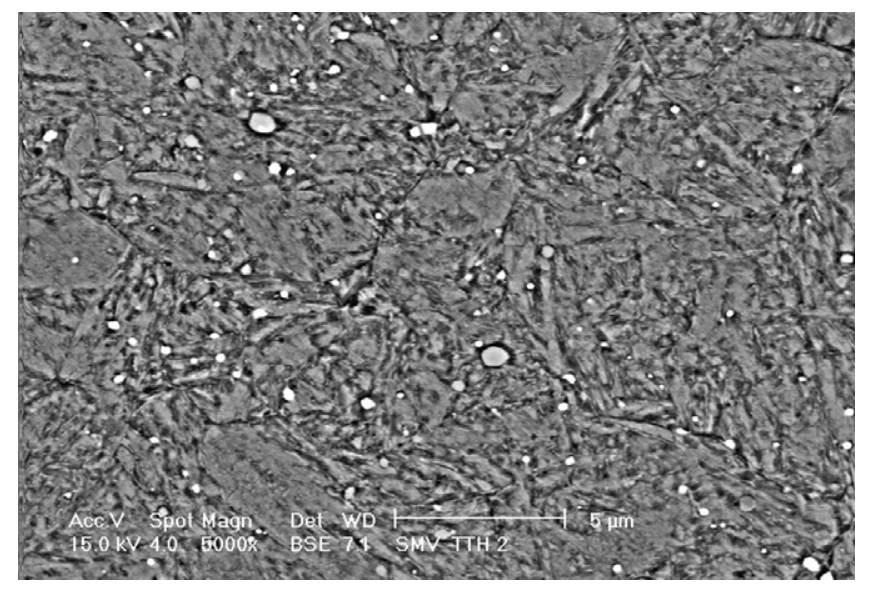

Fig. 5. SEM image showing numerous undissolved tungsten carbides (Nital etch) in the $\mathrm{W}$ grade.

Table 3

Distribution of the different types of carbides among the three populations for any considered grade

\begin{tabular}{clll}
\hline & $\begin{array}{l}\text { First } \\
\text { population } \\
(\sim 1.5 \mathrm{~nm})\end{array}$ & $\begin{array}{l}\text { Second } \\
\text { population } \\
(\sim 15 \mathrm{~nm})\end{array}$ & $\begin{array}{l}\text { Interlath + primary } \\
\text { carbides }\end{array}$ \\
\hline $\begin{array}{rll}\mathrm{NbC}, \mathrm{Fe}_{3} \mathrm{~W}_{3} \mathrm{C}, \\
(\mathrm{Cr}, \mathrm{Fe})_{23} \mathrm{C}_{6}\end{array}$ & & & $\checkmark$ \\
$\mathrm{VC}, \mathrm{Fe}_{3} \mathrm{Mo}_{3} \mathrm{C}$ & $\checkmark$ & $\checkmark$ & $\checkmark$ \\
$(\mathrm{Cr}, \mathrm{Fe})_{7} \mathrm{C}_{3}$ & $\checkmark$ (small & $\checkmark$ & \\
$(\mathrm{Fe}, \mathrm{Cr})_{3} \mathrm{C}$ & quantity) & & $\checkmark$ \\
\hline
\end{tabular}

MoMoCo) as indicated in Table 3. According to SANS results, small quantities of $\mathrm{M}_{7} \mathrm{C}_{3}$ carbides observed by TEM can be neglected. Results are presented in Table 4.
A second calculation is proposed using the well-known "magnetic hole" method: The precipitates $\mathrm{VC}$ and $\mathrm{Fe}_{3} \mathrm{Mo}_{3} \mathrm{C}$ are assumed to be non-magnetic and acting as magnetic holes in the ferromagnetic matrix. For the $\mathrm{Fe}_{3} \mathrm{Mo}_{3} \mathrm{C}$ carbide, the saturation magnetization calculated using results obtained by Tsuchida [18] is negligible $\left(4.6 \times 10^{-3} \mathrm{~T}\right)$ in comparison with the martensitic matrix. The "magnetic hole" method consists of subtracting the parallel (to the magnetic field) scattered intensity from the perpendicular one. In the case of non-magnetic particles, the volume fraction is independent of the chemistry of carbides. The contrast only depends on the magnetic moment and the atomic volume of the matrix:

$$
\begin{aligned}
I^{\prime}(q)= & I_{\perp}-I_{\|}=f_{\mathrm{p}}\left[\Delta \rho_{\mathrm{mag}}^{2}\right] \\
& \times \frac{\int_{0}^{\infty} h(R) V^{2}(R) F^{2}(q, R) \mathrm{d} R}{\int_{0}^{\infty} h(R) V(R) \mathrm{d} R} \text { and } \Delta \rho_{\mathrm{mag}}=-\frac{b^{\mathrm{m}}}{v_{\mathrm{at}}^{\mathrm{m}}}
\end{aligned}
$$

Two volume fraction estimations are given in Table 4. For lower Mo content (1.2-1.3 wt.\%), the values obtained with the assumption of $\mathrm{VC}$ carbides are in agreement with those corresponding to the magnetic hole volume fraction deduced from the magnetic scattering. The excellent agreement confirms that the first population mainly contains vanadium carbides. This is obviously not the case for grades with higher molybdenum content [12]. In this case, according to EDXS and XRD results which show that both vanadium and molybdenum carbides precipitate, a mixing law is proposed with the following hypotheses:

- The total scattered intensity is considered at first approximation to be the sum of the two carbide type contributions.

Table 4

Volume fractions of the first population of secondary carbides calculated using the magnetic hole and the chemical composition (VC or mixed

\begin{tabular}{|c|c|c|c|c|c|c|}
\hline \multirow[t]{2}{*}{ Grade } & \multirow[t]{2}{*}{ Tempering temperatures $\left({ }^{\circ} \mathrm{C}\right)$} & \multirow{2}{*}{$\frac{\text { Magnetic hole }}{f_{\mathrm{p}}^{\mathrm{MH}}(\%)}$} & \multirow{2}{*}{$\frac{\text { Hypothesis VC }}{f_{\mathrm{p}}^{\mathrm{VC}}(\%)}$} & \multicolumn{3}{|c|}{ Hypothesis "mixing law" } \\
\hline & & & & $f_{\mathrm{p}}^{\mathrm{VC}, \operatorname{mix}}(\%)$ & $f_{\mathrm{p}}^{\mathrm{Fe}_{3} \mathrm{Mo}_{3} \mathrm{C}, \operatorname{mix}}(\%)$ & $f_{\mathrm{p}}^{\text {total,mix }}(\%)$ \\
\hline \multirow[t]{2}{*}{ Reference } & $550 / 605$ & 0.44 & 0.44 & - & - & - \\
\hline & $550 / 595$ & 0.66 & 0.61 & - & - & - \\
\hline \multirow{2}{*}{ W } & $550 / 605$ & 0.50 & 0.47 & - & - & - \\
\hline & $550 / 610$ & 0.27 & 0.27 & - & - & - \\
\hline \multirow[t]{2}{*}{ MoMo } & $550 / 605$ & 0.86 & - & 0.53 & 0.45 & 0.98 \\
\hline & $550 / 615$ & 0.47 & - & 0.28 & 0.26 & 0.54 \\
\hline \multirow[t]{3}{*}{ MoMoCo } & $550 / 605$ & 0.98 & - & 0.43 & 0.68 & 1.11 \\
\hline & $550 / 625$ & 0.26 & - & 0.16 & 0.13 & 0.29 \\
\hline & $550 / 605$ & 0.48 & 0.48 & - & - & - \\
\hline $\mathrm{Ni}$ & $550 / 605$ & 0.37 & 0.37 & - & - & - \\
\hline $\mathrm{NiNi}$ & $550 / 605$ & 0.19 & 0.20 & - & - & - \\
\hline Mo & $550 / 605$ & 0.88 & - & 0.49 & 0.51 & 1.00 \\
\hline \multirow[t]{2}{*}{ VV } & $550 / 605$ & 1.14 & 1.12 & - & - & - \\
\hline & $550 / 615$ & 1.02 & 1.01 & - & - & - \\
\hline Co & $550 / 605$ & 0.50 & 0.47 & - & - & - \\
\hline NiMo & $550 / 605$ & 0.36 & 0.35 & - & - & - \\
\hline NiW & $550 / 605$ & 0.40 & 0.38 & - & - & - \\
\hline $\mathrm{NiV}$ & $550 / 605$ & 0.78 & 0.78 & - & - & - \\
\hline
\end{tabular}
$\mathrm{VC}+\mathrm{Fe}_{3} \mathrm{Mo}_{3} \mathrm{C}$ ) hypotheses 
- The smallest precipitates can only include VC or $\mathrm{Fe}_{3} \mathrm{Mo}_{3} \mathrm{C}$ carbides.

- Both types of precipitate can be described by the same form factor (spherical shape) and the precipitates sizes follow the same distribution.

- The differentiation of carbides is carried out in the calculations of the contrast and the volume fractions.

Considering the above-mentioned hypothesis, factor $C$ for the scattered intensity, respectively perpendicular and parallel to the magnetic field can be approximated by the following expressions:

$$
\begin{aligned}
& C_{\perp}^{\text {total }}=C_{\perp}^{\mathrm{VC}}+C_{\perp}^{\mathrm{Fe}_{3} \mathrm{Mo}_{3} \mathrm{C}}=f_{\mathrm{p}}^{\mathrm{VC}}\left[\Delta \rho_{\text {nucl, } \mathrm{VC}}^{2}+\Delta \rho_{\mathrm{mag}, \mathrm{VC}}^{2}\right] \\
& +f_{\mathrm{p}}^{\mathrm{Fe}_{3} \mathrm{Mo}_{3} \mathrm{C}}\left[\Delta \rho_{\text {nucl, } \mathrm{Fe}_{3} \mathrm{Mo}_{3} \mathrm{C}}^{2}+\Delta \rho_{\mathrm{mag}, \mathrm{Fe}_{3} \mathrm{Mo}_{3} \mathrm{C}}^{2}\right] \\
& C_{\|}^{\text {total }}=C_{\|}^{\mathrm{VC}}+C_{\|}^{\mathrm{Fe}_{3} \mathrm{Mo}_{3} \mathrm{C}}=f_{\mathrm{p}}^{\mathrm{VC}}\left[\Delta \rho_{\text {nucl, } \mathrm{VC}}^{2}\right] \\
& +f_{\mathrm{p}}^{\mathrm{Fe}_{3} \mathrm{Mo}_{3} \mathrm{C}}\left[\Delta \rho_{\text {nucl, } \mathrm{Fe}_{3} \mathrm{Mo}_{3} \mathrm{C}}^{2}\right]
\end{aligned}
$$

From Eq. (5) and introducing the $A$-ratio (Eq. (3)), the volume fraction of each type of carbide is given by:

$$
\begin{aligned}
& f_{\mathrm{p}}^{\mathrm{Fe}_{3} \mathrm{Mo}_{3} \mathrm{C}}=\frac{C_{\perp}^{\text {total }}-C_{\|}^{\text {total }} A^{\mathrm{VC}}}{\Delta \rho_{\text {nucl, } \mathrm{Fe}_{3} \mathrm{Mo}_{3} \mathrm{C}}^{2}\left(A^{\mathrm{Fe}_{3} \mathrm{Mo}_{3} \mathrm{C}}-A^{\mathrm{VC}}\right)} \\
& f_{\mathrm{p}}^{\mathrm{VC}}=\frac{C_{\|}^{\text {total }} A^{\mathrm{Fe}_{3} \mathrm{Mo}_{3} \mathrm{C}}-C_{\perp}^{\text {total }}}{\Delta \rho_{\text {nucl, } \mathrm{VC}}^{2}\left(\mathrm{~A}^{\mathrm{Fe}_{3} \mathrm{Mo}_{3} \mathrm{C}}-\mathrm{A}^{\mathrm{VC}}\right)}
\end{aligned}
$$

Results are given in Table 4. For the magnetic hole method, the estimated error obtained for the volume fraction is linked to the counting statistics and the selected adjustment model (particle shape and size distribution). Despite the extreme experimental conditions, the estimated error is less than $10 \%$. When the chemical composition of the particles is involved in the calculation (contrasts should be determined), an additional error caused by deviations from the stoichiometry and from the ideal composition (substitution) should be evaluated. Considering the extreme experimental values of the chemical composition (EDXS) and the crystallographic structures (XRD), the error still remains below $10 \%$ for the vanadium carbide but reaches $20 \%$ for the $\mathrm{Fe}_{3} \mathrm{Mo}_{3} \mathrm{C}$ carbide.

The values found by supposing a mixing law are comparable to those obtained by considering only magnetic holes. They are nevertheless systematically slightly higher than the magnetic hole volume fraction $(15 \%)$ but this variation can be justified by imprecise evaluations of the various parameters necessary for the contrasts calculation (variation of the stoichiometry of carbides, atomic volume variation according to chemical composition, etc.). These results clearly show that the volume fraction of vanadium carbides in Mo, MoMo and MoMoCo grades is quite close to the value obtained in the reference grade showing that molybdenum addition does not interfere with vanadium carbide precipitation during tempering. Therefore, in spite of the assumptions made concerning the particle distribution, the adopted method gives reliable results.

Fig. 6 shows that only molybdenum and vanadium additions strongly increase the volume fraction of the nano-size population. Cobalt addition has no effect on the three populations in the reference grade. However, a significant increase in the volume fraction of molybdenum carbides is observed when cobalt is associated with molybdenum: $0.68 \%$ compared with $0.45 \%$ for the MoMo grade (Table 4). The complex effect of cobalt on the dislocations structure and consequently on the density and nature of nucleation sites of precipitation has already been investigated and reported in the literature [6,8,19-21] and will not be discussed further on in this paper. Nickel addition significantly decreases the volume fraction of the first population. Conversely, a slight increase in the volume fraction of the second population is observed. As nickel remains in solid

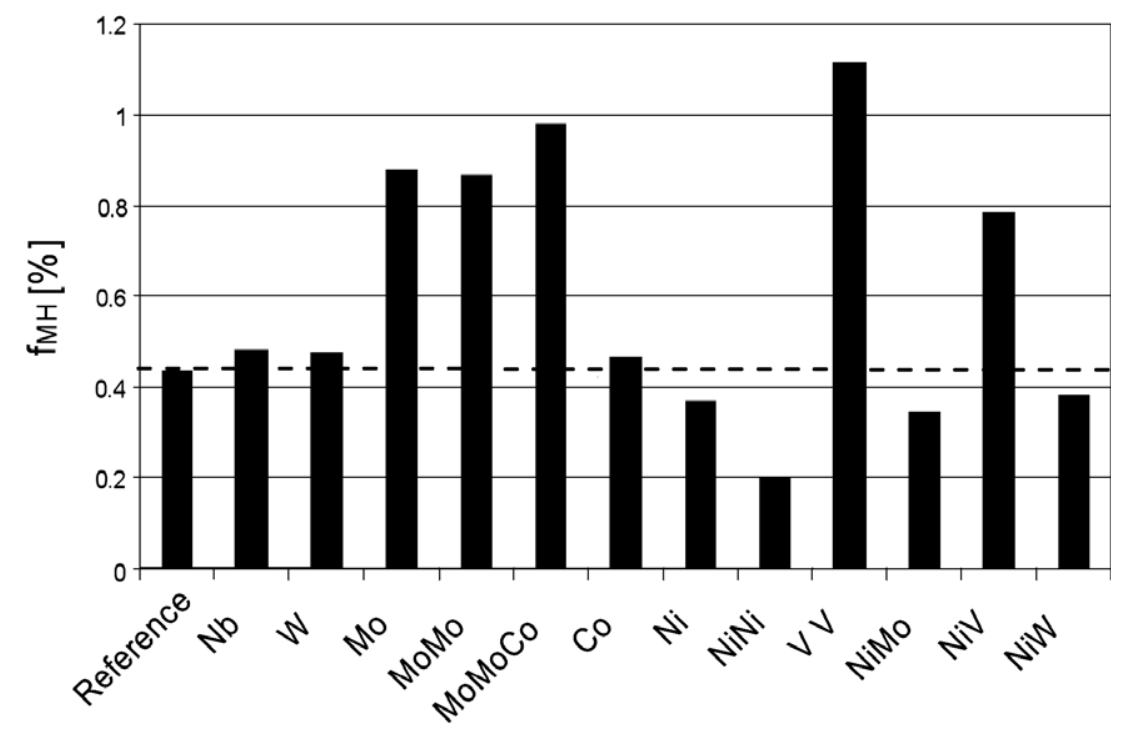

Fig. 6. Influence of alloying elements on the volume fraction of the first population calculated using the magnetic hole $\left(f_{\mathrm{MH}}\right)$ hypothesis. 
solution during tempering, several hypotheses concerning the modification of tempering kinetics can be formulated. The best-known explanation is that nickel decreases the solubility of carbon in the martensitic matrix leading to a greater supersaturation effect. The higher carbon supersaturation promotes the formation of alloyed carbides and then accelerates the secondary hardening process $[22,23]$.

In comparison with the reference steel, a simple calculation of mass conservation shows that all the added vanadium forms small carbides (radius $\approx 1.5 \mathrm{~nm}$ ) without any modification of larger size populations for the VV grade, showing that the adopted criterion of austenitizing temperature (cf. Section 2.1) calculation is relevant [12]. For Mo, MoMo and MoMoCo grades, $\mathrm{Fe}_{3} \mathrm{Mo}_{3} \mathrm{C}$ carbides were identified by electron diffraction (Fig. 4), XRD and EDXS. Only secondary molybdenum carbides are formed in the Mo grade. Conversely, molybdenum carbides were observed in every population for MoMo and MoMoCo grades, as shown in Fig. 7. Moreover, the higher content of molybdenum obviously results in excess primary carbides. Indeed, no increase in the quantity of secondary carbides was detected in comparison with the Mo grade.

To conclude, only vanadium, molybdenum and nickel modify the secondary precipitation and then mainly the first population (radius $\approx 1.5 \mathrm{~nm}$ ). Assuming a spherical shape for every population of carbides, particle number density can be deduced from the volume fraction estimation obtained from SANS results and from the total weight fraction measured after the dissolution of the matrix. Results are given in Table 5 for the reference grade. The particle number density of the first population is more than 100 times higher than the second population number density. As the recovery of martensitic steels during tempering or fatigue testing is mainly due to the rearrangement of the dislocation structure inherited from the quench results in a reduction of the dislocation density [5,24], the first popula-
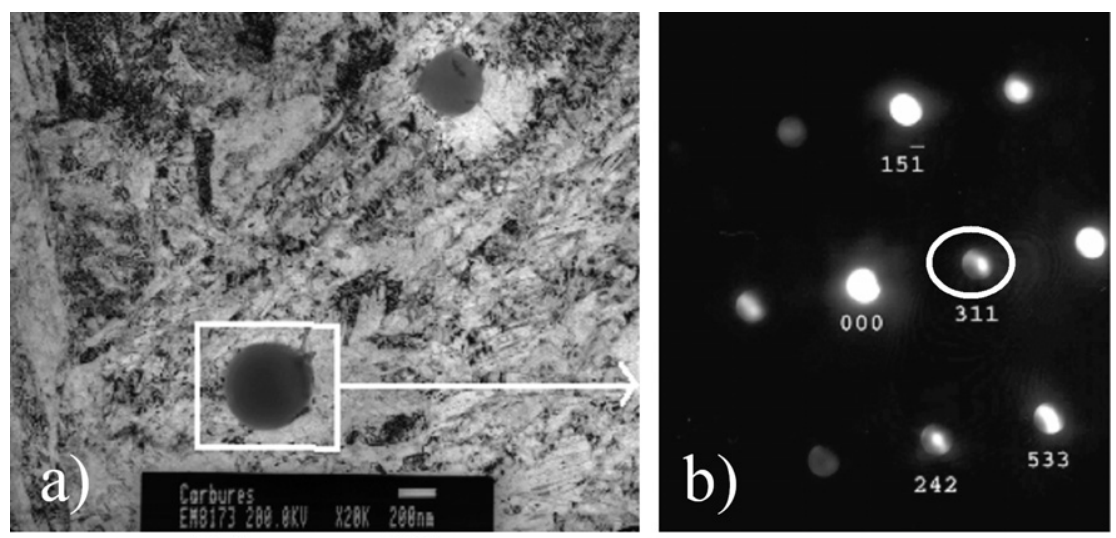

Primary carbide
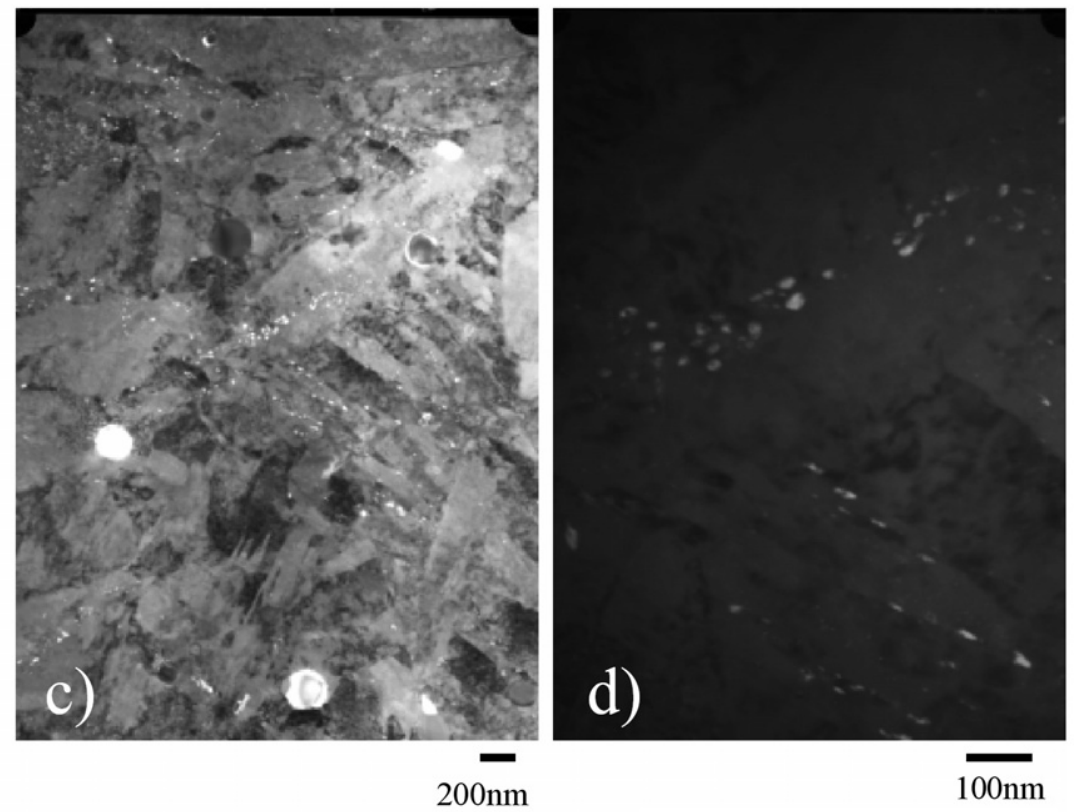

Secondary carbides

Fig. 7. (a) Bright field TEM image showing primary molybdenum carbides, (b) corresponding diffraction pattern, and (c) and (d) dark field TEM images showing the precipitation of both primary and secondary molybdenum carbides (MoMo grade), respectively. 
Table 5

Estimation of particle number density $(N)$ and mean inter-particle distance between a particle and its two or three neighbours $(d)$ for each population of the reference grade

\begin{tabular}{|c|c|c|c|}
\hline & First population & Second population & Interlath + primary carbides \\
\hline Average radius (nm) & $\approx 1.5$ & $\approx 15$ & $r>80$ \\
\hline$f_{\mathrm{p}}(\%)$ & $0.4<f_{\mathrm{p}}<0.5$ & $1.5<f_{\mathrm{p}}<2.5$ & $2<f_{\mathrm{p}}<3$ \\
\hline$N=\frac{f_{\mathrm{p}}}{(4 / 3) \pi r^{3}}\left(\mathrm{~m}^{-3}\right)$ & $2 \times 10^{23}<N<4 \times 10^{23}$ & $10^{21}<N<2.10^{21}$ & $N<10^{19}$ \\
\hline$d=1.18 r \sqrt{2 \pi / 3 f_{\mathrm{p}}}(\mathrm{nm})$, see Refs. & $36<d<41$ & $160<d<210$ & $\begin{array}{l}\text { Above the mean width of martensitic } \\
\text { laths }\end{array}$ \\
\hline
\end{tabular}

tion seems to be the relevant microstructural parameter to improve the material. Indeed, small carbides offer numerous obstacles to the dislocation motion thereby preventing the quick recovery observed for plain carbon steels. The next section aims to show how the first population influences mechanical properties.

\subsection{Relationship between volume fraction of small carbides and mechanical properties}

The influence of secondary carbides on the mechanical properties of martensitic steels has been widely investigated in the literature $[6,8,27,28]$ (essentially tensile properties, creep and more rarely fatigue). The role of carbides in dislocation rearrangement during tempering has also been described in steels with high chromium content for high temperature applications [7,29]. However, work was performed on over-aged steels and only little information exists on the effect of small carbides in early stage of the precipitation sequence for tempering conditions very close to the second hardening peak. Above all, crossing mechanisms of secondary carbides by dislocations are still unclear even if the first in situ TEM experiments [30] (tensile test performed inside the microscope at room temperature) have shown a clear planar bypassing mechanism on the reference grade. Conversely, as shown in Fig. 8, the pinning of dislocations on small carbides has been clearly observed on the reference grade by TEM observations. However, as previously mentioned, the first population is partially seen by TEM and the major area of the observations concerns the right side of the Gaussian distribution.

\subsubsection{Yield strength}

In Fig. 9, the yield strength measured at $550{ }^{\circ} \mathrm{C}$ is shown as a function of the volume fraction of precipitates calculated by SANS, using the magnetic hole method. Stress measurements were obtained within a scatter band less than $\pm 10 \mathrm{MPa}$ taking into account the load sensor accuracy as well as the temperature gradient along the specimen. The curve can be divided into two different parts. For volume fraction values lower than $0.6 \%$, a strong correlation is observed with a large increase in the yield strength from $650 \mathrm{MPa}$ to $950 \mathrm{MPa}$. Above $0.6 \%$, a saturation of the yield strength is observed particularly for grades containing a first population which include only vanadium carbides. Increasing the number density of small carbides becomes inefficient. Conversely, for grades containing 2.7 wt.\% Mo (MoMo, MoMoCo), a slight increase in the yield strength is measured above $f_{\mathrm{MH}}=0.6 \%$ (Fig. 9).

\subsubsection{Charpy impact energy}

Scanning electron microscope analysis of the surface rupture shows a ductile transgranular rupture for every grade (Fig. 10). Moreover, scarce zones of interlath and intergranular rupture are observed but this conclusion is also valid for all grades. So, no modification of the crack propagation mechanism was detected at the microscopic scale for the measured range of Charpy impact energy $(20-50 \mathrm{~J})$. Fig. 11 presents the relationship between the Charpy impact energy measured at room temperature and the volume fraction of the first population. Two major comments can be deduced from this figure:
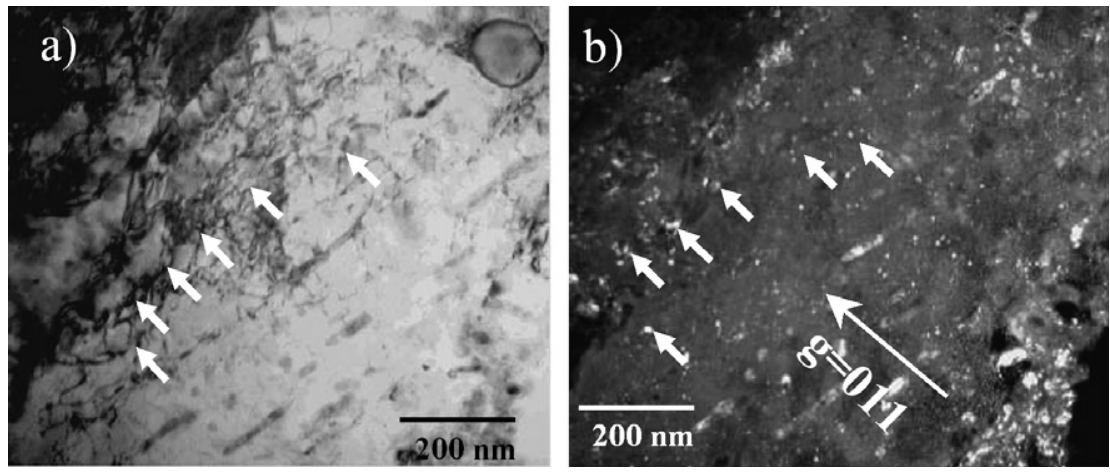

Fig. 8. (a) Bright field TEM image of a martensitic lath showing the pinning of dislocations on small vanadium carbides (reference grade). (b) Dark field

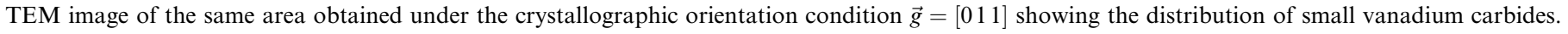




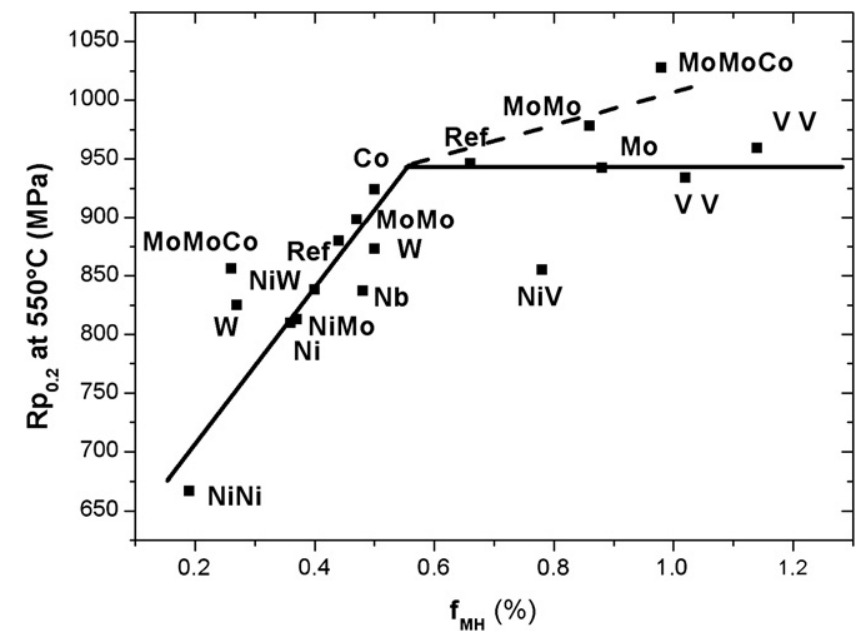

Fig. 9. Experimental yield strength measured at $550{ }^{\circ} \mathrm{C}$ as a function of the volume fraction of the first population estimated using the magnetic hole hypothesis (two tempering conditions for several grades).

- For grades only containing vanadium and chromium carbides, a strong decrease in the Charpy test results is observed with the volume fraction of the first population showing that number density of small precipitates influences both impact energy and yield strength, giving a microstructural explanation of the compromise between the two properties.

- For grades containing additional larger particles (niobium, tungsten or molybdenum carbides), a significant detrimental effect on Charpy impact energy is observed. Considering a similar microstructure for all grades at a larger scale, the formation of additional larger carbides (second population or primary carbides, see Table 5) promotes easier crack path, as proposed by different authors [31-33].

The result obtained for the Mo grade is interesting to emphasize. Indeed, experimental results showed that the volume fraction of the first population is increased by the precipitation of small molybdenum carbides. Larger size

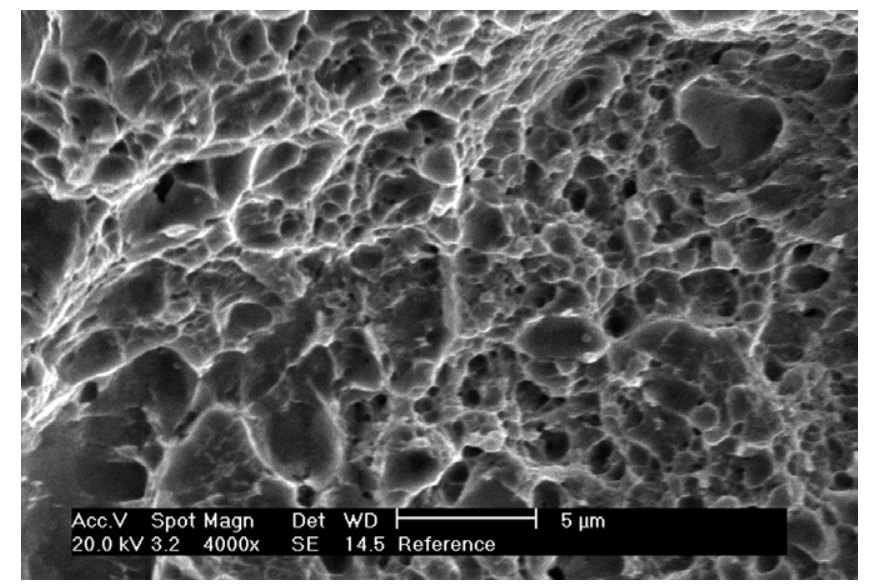

Fig. 10. Scanning electron microscope image of the surface rupture showing a ductile transgranular rupture of the reference grade at room temperature.

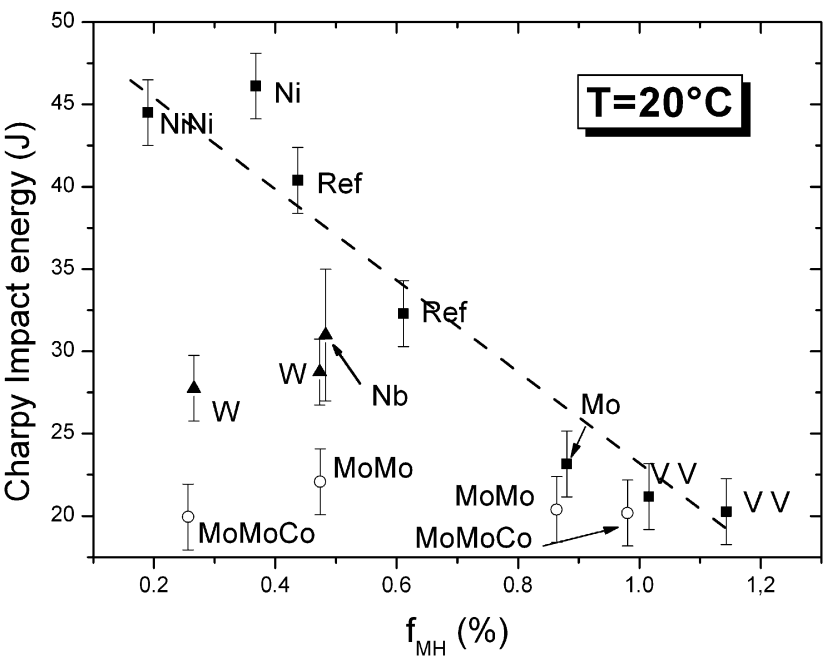

Fig. 11. Charpy impact energy measured at room temperature as a function of the volume fraction of the first population estimated using the magnetic hole hypothesis (two tempering conditions for several grades).

populations were not modified. Fig. 10 shows that the Charpy impact energy of the Mo grade is very close to the linear law describing the evolution of impact energy of grades containing vanadium and chromium carbides (reference, $\mathrm{Ni}, \mathrm{NiNi}, \mathrm{VV}$ ). In this case, impact energy does not depend on the chemistry or crystallography of small carbides but only the size and the quantity of particles seem to have a significant influence.

\section{Discussion: effects of vanadium and molybdenum carbides on yield strength}

Experimental results show that the best compromise on the mechanical properties can be obtained by combining a limited content of both vanadium and molybdenum for fixed austenitizing conditions leading to a suitable prior austenitic grain size ensuring long term service at high temperature. Including a higher molybdenum content results in the formation of larger precipitates involving a hugely detrimental effect on the Charpy impact energy. However, the compromise can be modified by increasing the austenitizing temperature above $1000^{\circ} \mathrm{C}$ in order to dissolve a higher quantity of $\mathrm{M}_{6} \mathrm{C}$ carbides. This is a reasonable way to increase the volume fraction of secondary carbides. Nevertheless, the associated loss of properties (fatigue, creep, impact toughness) should be further investigated, as the mechanisms involved remain unclear. Increasing the vanadium content induced an intense precipitation of small secondary carbides which is precisely the main goal. When the volume fraction is increased, the inter-particle spacing is lowered. As a consequence, the curvature of a dislocation crossing a particle increases and the stress necessary to bypass the particle increases as well. However, above a volume fraction of $0.6 \%$, yield strength, tensile strength as well as hardness [34] do not increase any more. The following discussion aims to propose a relevant mechanism associated with the distribution and the number 
density of particles in order to explain the saturation phenomenon.

First, further investigations requiring complex in situ TEM observations need to be performed to analyse the dislocation arrangement in grades containing a high volume fraction of small secondary carbides. Indeed, even though the Orowan mechanism was clearly identified by Mebarki [30], results concerning the possible shearing mechanism of small vanadium carbides presenting a well-defined orientation relationship with the matrix $[8,35]$, are not available in the literature. As all the vanadium carbides belonging to the first population have nearly the same shape and size, all the particles could be sheared with the same stress explaining the saturation.

Conversely, the considerable work of Mohles et al. [3638] on the computer simulations of dislocation glide in over-aged spherical particle strengthened materials has shown the different configurations taken by the dislocations in relation to the following parameters: the volume fraction of particles, the mean particle radius and the degree of randomness of the distribution. Orowan process controlled dislocation glide in a single crystal (no climb, no cross-slip) containing spherical precipitates is computer simulated.

One main conclusion obtained by Mohles et al. deals with the tendency to create more Orowan islands in obstacle field with high volume fraction. Even if the simulated conditions considered by these authors are different from our investigated cases (larger radius and volume fraction of particles), our grades obviously contain a larger number of obstacles $\left(\sim 3 \times 10^{23} \mathrm{~m}^{-3}\right)$ than the simulated cases considered by Mohles et al. (less than $3 \times 10^{21} \mathrm{~m}^{-3}$ ) leading to the hypothesis of Orowan island formation. Indeed, the relevant microstructural parameter is definitively the number density of obstacles to the dislocation glide. The volume fraction of precipitates has a scientific sense if every single particle influences the dislocation motion and consequently participates in strengthening. This is not the case when Orowan islands are formed, as several particles are enclosed in a common dislocation loop. In this case, Figs. 9 and 11 should be modified considering the number density of particles really contributing to the pinning of dislocations, which may progressively saturate when the volume fraction increases.

The heterogeneity of the particle distribution is another important factor increasing the tendency to Orowan island formation [37]. Carbides embedded in the martensitic matrix, as well as carbides extracted from the bulk, were observed by TEM. From both kinds of preparation, a non-uniform arrangement is qualitatively observed. From observation of thin foils, the heterogeneity may be partially associated with crystallographic aspects as vanadium carbides present a defined coherency with the martensitic matrix [8,35] (Baker-Nutting). The relevant information is obtained with orientation conditions corresponding to observation of the glide plane of dislocations. However, the high dislocation density $\left(\sim 10^{16} \mathrm{~m}^{-2}[5]\right)$ impedes any reliable statistics.

Easier TEM observations can be performed using replicas, but the crystallographic information is lost. Assuming that chemical etch and the subsequent preparation gives identical results on the whole surface of the replica, it can be concluded that the distribution of small precipitates is heterogeneous, as shown in Figs. 12 and 3a. The proposed mechanism inducing the yield strength saturation deals with the heterogeneity of vanadium distribution within the martensitic lath. Indeed, it has been shown that vanadium carbides form by separate nucleation within the martensitic lath on dislocations inherited from the martensitic transformation [8]. The incomplete dissolution of primary
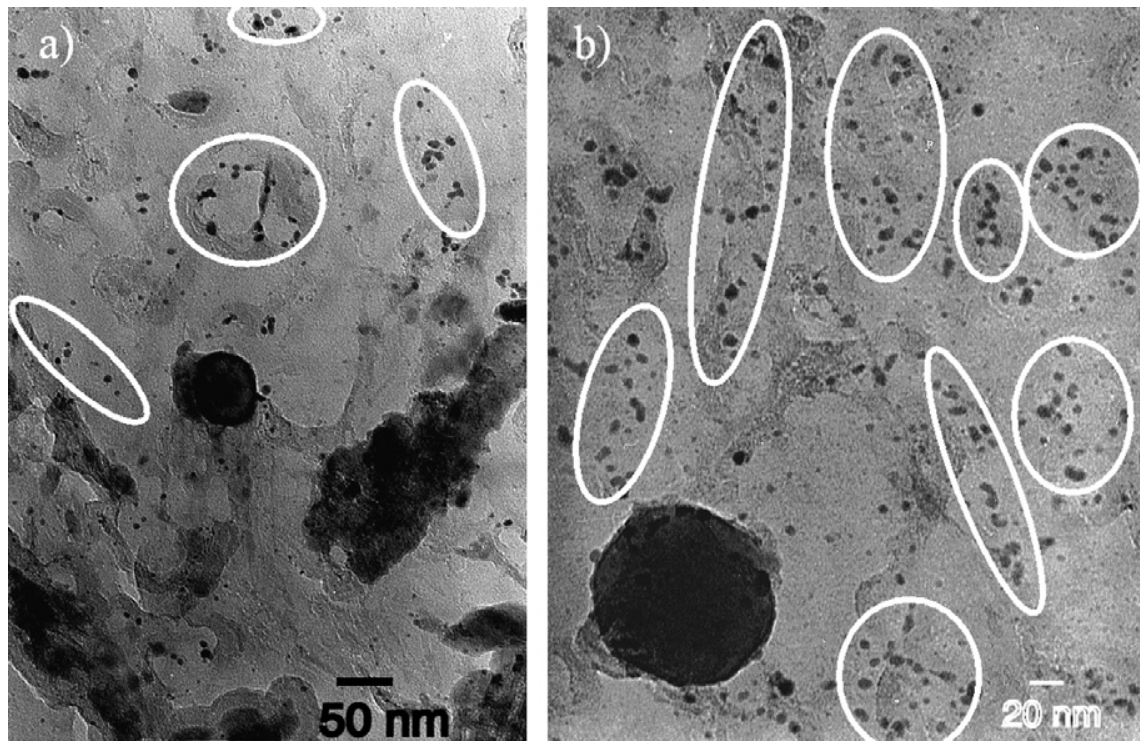

Fig. 12. Bright field TEM images showing the heterogeneous distribution of secondary vanadium carbides in the reference grade for a Nital etch time of (a) $5 \mathrm{~s}$ and (b) $15 \mathrm{~s}$ during the replica preparation. High number density zones are marked. 
vanadium carbides during austenitization results in a heterogeneous concentration of vanadium with a higher content near the boundary of undissolved carbides or near the areas where primary vanadium carbides are totally dissolved. Indeed, a calculation performed with DICTRA ${ }^{\mathrm{TM}}$ software with TCFE3 and MOB2 thermodynamic databases for the reference grade shows that the vanadium diffusion coefficient in austenite is equal to $D_{\mathrm{AISIH} 11}^{\mathrm{V}}=3 \times 10^{-16} \mathrm{~m}^{-2} \mathrm{~s}^{-1}$. Considering the experimental austenitization duration $t(1800 \mathrm{~s})$ at $T=1253 \mathrm{~K}$, the diffusion length $l=\sqrt{2 D t}$ is about a micrometre. This value falls between the average length and width of a martensitic lath and is significantly lower than the mean inter-particle distance in primary carbides. Considering that $l$ is overestimated, as the dissolution of primary VC carbides is not instantaneous, it is absolutely clear that vanadium concentration at the end of the austenitization is heterogeneous. This heterogeneity remains during the following steps of the heat treatment. Consequently secondary vanadium carbides that preferentially formed in rich zones of vanadium are heterogeneously distributed. Increasing the vanadium content leads to an increase in the volume fraction of vanadium carbides in these preferential zones up to a certain extent as the enrichment of vanadium particles results in a corresponding depletion in the surrounding matrix. As the distance between rich zones of vanadium is not modified by increasing the vanadium content, the saturation may be explained by the constant "mean free path" of dislocations between zones presenting a high density of particles. In this case, increasing the volume fraction of precipitates only increases the heterogeneity of the distribution, which is inefficient regarding the flow resistance.

\section{Conclusion}

The volume fraction of small secondary carbides (radius $=1.5 \mathrm{~nm}$ ) identified by SANS, XRD, TEM and EDXS directly influences the mechanical strength as well as the Charpy impact energy. This nanometric scale parameter controls the well-known compromise between mechanical strength and toughness. Consequently, an adjustment of chemical composition resulting in the modification of the number density of small carbides is required to improve the set of mechanical properties. Two different routes have been investigated:

- Modification of the chemical composition of small carbides involved in the high temperature mechanical resistance: additions of $\mathrm{W}, \mathrm{Nb}$ and $\mathrm{Mo}(2.7 \mathrm{wt} . \%)$. As the austenitization conditions could not be modified to an extent where sufficient dissolution occurred, primary carbides were found in quantities that a detrimental effect on the Charpy impact energy was observed.

- As vanadium carbides prevent the quick growth of the existing austenitic grains, complementary addition of vanadium results in a significant increase in the volume fraction of small secondary precipitates. However, the effect on the mechanical strength is limited, probably owing to the heterogeneity of vanadium concentration within the matrix.

Progress in improving the mechanical properties of high strength steels probably lies in introducing other types of homogeneous particle distribution, such as oxides or intermetallics depending on the thermo-mechanical loading. This route has the advantage of completely separating the austenitization conditions leading to a correct austenitic grain size with the precipitation occurring during tempering. In this direction, a compromise in the properties of steels including both types of precipitation (secondary hardening carbides and intermetallic precipitates NiAl) is currently being studied [39-41].

\section{Acknowledgements}

Authors gratefully acknowledge AUBERT \& DUVAL (A\&D) for supplying the steels and for financial support. Special thanks are given to Mr A. Grellier, Mr P.E. Richy, Mr T. Turpin, Mrs G. Dautheribes and Mrs M.F. Gervais from A\&D, Prof. A. Coujou, Dr. F. Pettinari-Sturmel and Dr J. Douin from CEMES-CNRS for fruitful discussions. The authors wish to thank F. Rossi from Ecole des Mines d'Albi-Carmaux (EMAC) for invaluable help in the realization and analysis of mechanical tests and $\mathrm{Mr} \mathrm{R}$. Moore for improvement in the English of the paper.

\section{References}

[1] Fournelle RA, Grey EA, Fine ME. Metall Trans 1976;7A:669.

[2] Kanazawa K, Yamaguchi K, Kobayashi K. Mater Sci Eng 1979;40:89.

[3] Vogt JB, Degallaix G, Foct J. Fatigue Frac Eng Mat Struct 1988;11:435.

[4] Zhang Z, Delagnes D, Bernhart G. Int J Fatigue 2002;24:635.

[5] Mebarki N, Delagnes D, Lamesle P, Delmas F, Levaillant C. Mater Sci Eng A 2004;387-389:171.

[6] Roberts GA, Cary RA. Tool steels. fourth ed. Metals Park [OH]: American Society for Metals; 1980.

[7] Wang ZG, Rahka K, Nenonen P, Laird C. Acta Metall 1985;33: 2129.

[8] Honeycombe RWK, Bhadeshia HKDH. Steels: microstructure and properties. 2nd ed. London: Edward Arnold; 1995.

[9] Delagnes D, Lamesle P, Mathon MH, Mebarki N, Levaillant C. Mater Sci Eng A 2005;394:435.

[10] Pickering FB. Physical metallurgy and the design of steels. London: Applied Science Publishers; 1978.

[11] Delagnes D. PhD Thesis, Ecole Nationale Supérieure des Mines de Paris; 1998.

[12] Michaud P, Delagnes D, Lamesle P, Richy PE, Levaillant C. In: Kuzman K, editor. Proceedings 5th International Conference on Industrial Tools. Velenje, Slovenia: TECOS; 2005. p. 165.

[13] Dour G, Dargusch M, Davidson C, Nef A, St John D. In: Dahle A, editor. Proceedings conference light metals technology. Brisbane; 2003. p. 155.

[14] Kim C, Biss V, Hosford WF. Metall Trans 1982;13A:185.

[15] Cotton JP. In: Lindner P, Zemb T, editors. Neutron. X-ray and light scattering: introduction for an investigated tool for colloidal and polymeric system. Amsterdam: North Holland; 1991. p. 19. 
[16] Mathon MH, Barbu A, Dunstetter F, Maury F, Lorenzelli N, De Novion CH. J Nucl Mater 1997;245:224.

[17] Leitner H, Staron H, Clemens H, Marsoner S, Warbichler P. Mater Sci Eng A 2005;398:323.

[18] Tsuchida T. J Mater Sci 2001;36:1735.

[19] Dyson DJ, Keown SR. Acta Metall 1969;17:1095.

[20] Chandhok VK, Hirth JP, Dulis EJ. Trans TMS-AIME 1962;224:858.

[21] Gorynin IV, Rybin VV, Malyshevskiy VA, Semicheva TG, Sherokhina LG. Metal Sci Heat Treat 1999;41:377.

[22] Irvine KJ, Crowe DJ, Pickering FB. JISI 1960;195:386.

[23] Lee KB, Yang HR, Kwon H. Metall Mater Trans 2001;32A:1659.

[24] Pesicka J, Kuzel R, Dronhofer A, Eggeler G. Acta Mater 2003;51:4847.

[25] Kocks UF. Acta Metall 1966;14:1629.

[26] Daigne J, Guttmann M, Naylor JP. Mater Sci Eng 1982;56:1.

[27] Nutting J. JISI 1969;207:872.

[28] Maropoulos S, Paul JDH, Ridley N. Mater Sci Tech 1993;9:1014.
[29] Chang HJ, Tsai CH, Kai JJ. Int J Pres Ves Piping 1994;59:31.

[30] Mebarki N. PhD Thesis. Ecole Nationale Supérieure des Mines de Paris; 2003.

[31] Tomita Y. Mater Sci Tech 1990;6:349.

[32] Neri MA, Colas R. Mater Charact 2001;47:283.

[33] Briant CL. Mater Sci Tech 1989;5:138.

[34] Michaud P. PhD Thesis. Ecole Nationale Supérieure des Mines de Paris; 2006.

[35] Yamasaki S, Bhadeshia HKDH. Mater Sci Tech 2003;19:1335.

[36] Mohles V, Ronnpagel D, Nembach E. Comput Mater Sci 1999;16:144.

[37] Mohles V, Fruhstorfer B. Acta Mater 2002;50:2503.

[38] Mohles V. Mater Sci Eng A 2001;309-310:265.

[39] Garrison WM, Strychor R. Metall Trans 1988;19A:3103.

[40] Hamano R. Metall Trans 1993;24A:127.

[41] Erlach SD, Leitner H, Bischof M, Clemens H, Danoix F, Lemarchand D, et al. Mater Sci Eng A 2006;429:96. 